\title{
Effects of the antibiotic monensin and an inhibitor of methanogenesis on in vitro continuous rumen fermentations
}

\author{
BY G. STANIER AND A. DAVIES \\ Imperial Chemical Industries Ltd, Pharmaceuticals Division, Alderley Park, \\ Macclesfield, Cheshire SK10 4TG
}

(Received 3 March 1980 - Accepted 23 December 1980)

1. The effects of a methane inhibitor, ICI 111075, and a propionate enhancer, monensin, were studied using in vitro continuous fermenters.

2. Both compounds increased the yield of substrate energy, carbon and hydrogen in volatile fatty acids (VFA). This was mainly due to an increase in the molar proportion of propionic acid.

3. Improved yields of VFA were accompanied by reductions in methane production and microbial yield.

4. Since published information showed that monensin reduced rumen dilution rate in vivo an analogous in vitro system was proposed in which a high dilution rate control fermenter was compared with a monensin treated fermenter set to run at a low dilution rate.

5. Results showed that the general intrinsic microbial activity of the chemical manipulators was not affected by changes in dilution rate. Changing dilution rate in addition to chemical treatment however resulted in substantial modifications in the net effect on the fermentation.

6. The practical implications of reducing rumen dilution rate as a side effect of chemically manipulating the rumen fermentation could involve changes in food intake, increased importance of secondary fermentations and a reduced effect of nutrients not degraded in the rumen.

The use of chemicals to manipulate selectively the rumen fermentation, such that animal growth performance is improved, has been reviewed recently (Chalupa, 1977; 1979). Work to manipulate favourably energy transactions within the rumen has involved mainly two distinct classes of compound which either primarily inhibit methane production or enhance propionate production. Methane inhibitors generally also enhance propionate production since both processes are inversely related.

Numerous production trials have been done to demonstrate the growth-promoting efficacy of these chemicals. Whilst some trials have shown beneficial effects with methane inhibitors (Trei, Parish \& Scott, 1971; Trei \& Scott, 1971 a,b; Trei et al. 1972; Leibholz, 1975), others have shown little or no response (Sawyer et al. 1974; Cole \& McCroskey, 1975). One of the major problems with this type of compound, which are mainly halogenated methane analogues, has been the adaptation of the rumen micro-organisms after prolonged administration (Johnson, 1974; Clapperton, 1977). It has also been concluded that level of feeding, level of concentrate and feeding frequency could affect the efficacy of methane inhibitors (Cole \& McCroskey, 1975). The beneficial effects of the propionate enhancer, monensin, have been demonstrated extensively. Performance has been improved in cattle (Oliver, 1975; Davis \& Erhart, 1976; Potter et al. 1976; Raun et al. 1976; Turner et al. 1977) and lambs (Nockels et al. 1978; Joyner et al. 1979). Avoparcin, another propionate enhancer, improves both food conversion and daily gain in cattle (Johnson et al. 1979). Interestingly, monensin had no beneficial effect in this trial.

Studies to explain the effects of chemical manipulators on the rumen fermentation in terms of fermentation balances have been limited. In vitro studies have shown the effects of chloral hydrate (Van Nevel et al. 1969), sodium sulphite, chloral hydrate and hemiacetal of chloral and starch (Marty \& Demeyer, 1973) and monensin (Van Nevel \& Demeyer, 1977; Short, 1978) on the fermentation of carbohydrate to volatile fatty acids (VFA), carbon dioxide, hydrogen and methane. The use of batch culture (Van Nevel et al. 1969; Marty 
\& Demeyer, 1973; Van Nevel \& Demeyer, 1977) or semi-continuous batch culture (Short, 1978) may not be relevant to effects in the animal.

The development of a number of in vitro continuous fermentation systems has provided a method with which to study the rumen fermentation in detail under strictly-controlled conditions. One such system is Rusitec (Czerkawski \& Breckenridge, 1977) which is both simple and reliable and at present provides a good in vitro simulation of in vivo conditions. In addition to being able to quantify the effects of manipulators by means of fermentation balances the ability to control dilution rate precisely enables the effects of the latter to be determined.

The importance of dilution rate in determining the pattern and efficiency of rumen fermentation has been shown by infusing artificial saliva into the rumen of sheep (Harrison et al. 1974; Harrison et al. 1975) and by the inclusion of mineral salts in the diet (Thomson et al. 1975; Thomson et al. 1978). Whilst dietary administration of monensin has produced substantial reductions in rumen dilution rate in cattle (Lemenager et al. 1978) and sheep (Allen \& Harrison, 1979) other studies have shown no effect (Van Nevel \& Demeyer, 1979). Using the facilities provided by multiple continuous fermenters the effects of rumen manipulators and dilution rate can be studied separately or in combination. In the instance of monensin the latter situation may theoretically simulate the in vivo conditions best.

The aim of this study was to use a continuous fermentation system to compare and quantify the effects of a methane inhibitor, ICI 111075 and a propionate enhancer, monensin. The role of dilution rate in modifying the efficacy of these rumen manipulators was also investigated.

\section{EXPERIMEN TAL}

\section{Fermentation system}

The continuous fermenter used was based on the design described by Czerkawski \& Breckenridge (1977). Modifications included having six fermenters in a single unit with food containers attached via metal rods to a single beam which oscillated $50 \mathrm{~mm}$ vertically at 8 cycles/min to agitate the fermentation (Fig. 1). The overflow pipes were adjusted to give a liquid volume of 11 and a gas space of $150 \mathrm{ml}$. Buffer, $\mathrm{pH} 7$ (Bales et al. 1976; but omitting the acetic acid) was pumped continuously into each fermenter by a six-channel peristaltic pump (Proportioning pump; Technicon Instruments Ltd, London). Effluent liquid and gases were collected as described by Czerkawski \& Breckenridge (1977).

\section{General procedure}

Rumen fluid was obtained from two fistulated heifers given a hay-concentrate diet, pooled and filtered through four layers of muslin cloth. Strained fluid $(500 \mathrm{ml})$ was put into each fermentation vessel along with a nylon bag containing $50 \mathrm{~g}$ rumen solids and another bag containing the experimental diet of $10 \mathrm{~g}$ long hay and $2 \mathrm{~g}$ cattle concentrate. The gas phase was flushed with carbon dioxide (Expt 1) or high purity nitrogen (White Spot $\mathbf{N}_{2}$, British Oxygen Co. Ltd, Worsley, Manchester) in Expts 2 and 3. No gross differences in fermentation pattern were apparent with the two gases. Each fermenter was filled to 11 liquid volume by pumping buffer at the chosen experimental rate (cf. Czerkawski \& Breckenridge, 1977). Subsequently the basic sampling and feeding procedures described by Czerkawski \& Breckenridge (1977) were adopted. Gas samples $(2 \mathrm{ml})$ were withdrawn from the fermenter headspace using a syringe and a hypodermic needle inserted through a rubber suba-seal located in the top of the fermentation vessel. These samples were then analysed for percentage composition. Experiments consisted of a $7 \mathrm{~d}$ acclimatization period followed by daily administration of chemical manipulators for $25 \mathrm{~d}$. 


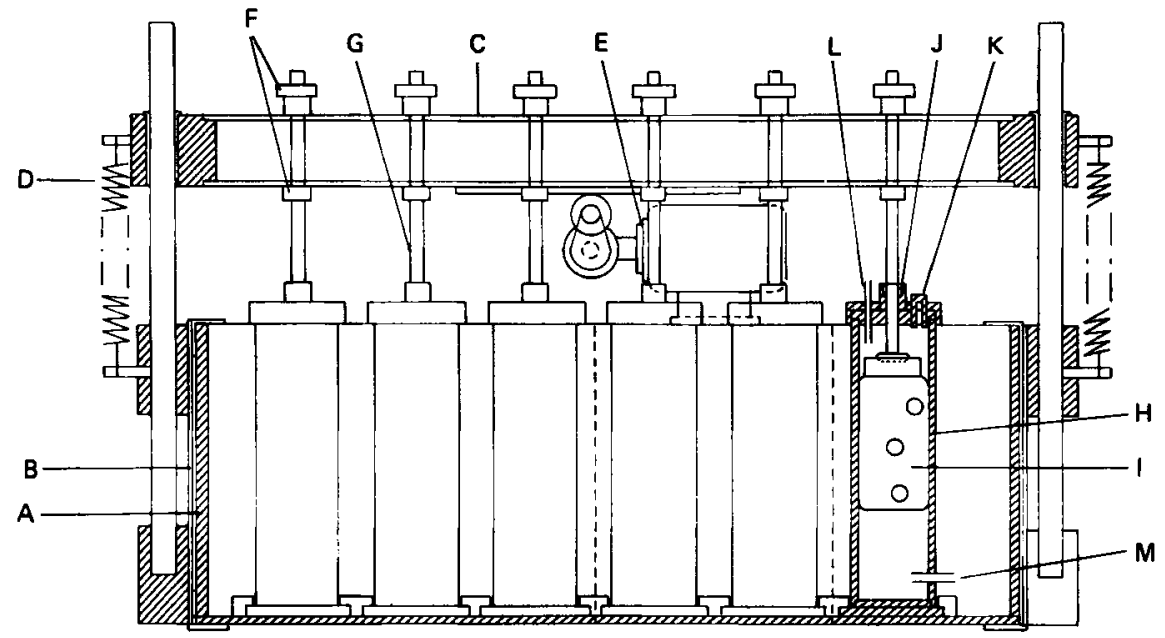

Fig. 1. Schematic diagram of a six vessel continuous fermentation system. A, Perspex tank; B, steel frame to support tank; C, oscillating beam; D, spring to aid downward movement; E, Parvalux motor/gear box; F, locking nuts; G, steel shaft; H, Perspex fermentation vessel; I, polyethylene bottle to contain nylon feed bags; J, gas-tight gland; K, suba-seal gas sampling gland; L, outlet pipe for liquid effluent and gases; $M$, inlet pipe for buffer.<smiles>O=C(O)c1ccc(OC(C(Cl)(Cl)Cl)C(Cl)(Cl)Cl)c(C(Cl)=[Ge])c1</smiles>

Fig. 2. ICI 111075, 2-trichloromethyl-4-dichloromethylene benzo[1,3] dioxin-6-carboxylic acid.

\section{Experimental procedures}

Expt 1 . Single fermenters were dosed daily with ICI 111075 (Fig. 2) at $2 \cdot 0,1.0$ and $0.5 \mu \mathrm{g} / \mathrm{ml}$ or monensin at $0.5 \mu \mathrm{g} / \mathrm{ml}$. Compounds were dissolved in ethanol and an equal volume of solvent was added to both control fermenters. All six fermenters were run at a dilution rate of $1 \cdot 0 / \mathrm{d}$. Total gas volume was not determined in this experiment and results were expressed as percentage composition.

Expt 2. Duplicate fermenters were dosed daily with ICI $111075(2.0 \mu \mathrm{g} / \mathrm{ml})$, monensin $(0.5 \mu \mathrm{g} / \mathrm{ml})$ or ethanol (controls). Dilution rate was $1 \cdot 0 / \mathrm{d}$.

Expt 3. Three fermenters were run at a dilution rate of $0.90 / \mathrm{d}$ and three others at $0.45 / \mathrm{d}$. In each group single fermenters were dosed daily with ICI $111075(2.0 \mu \mathrm{g} / \mathrm{ml})$, monensin $(0.5 \mu \mathrm{g} / \mathrm{ml})$ or ethanol (control).

\section{Analytical methods}

Gases were measured daily by a modification of the technique of Czerkawski \& Clapperton $(1968 a)$. The basic apparatus was a Pye 104 Katharometer Power supply and Katharometer detector (Pye Instruments Ltd, Cambridge). Column 1 was $0.46 \mathrm{~m} \times 6.4 \mathrm{~mm}$ glass packed with Porapak Q 80-100 mesh (Waters Associates Inc., Maple St, Milford, Mass. 01757, USA). The delay column was $7.62 \mathrm{~m} \times 3.2 \mathrm{~mm}$ in copper tubing and the final column was 
$1.52 \mathrm{~m} \times 6.4 \mathrm{~mm}$ in glass packed with Molecular Sieve 5A 80-100 mesh (Phase Separations Ltd, Deeside Industrial Estate, Queensferry, Clwyd CH5 2LR). The two separate columns and detector were housed in an insulated box at room temperature. The carrier gas was argon $(50 \mathrm{ml} / \mathrm{min})$. Samples were injected through a sampling valve with a loop of $1 \mathrm{ml}$ volume. The detector signal was processed by a Spectra Physics SP4000 Chromatography Data System (Spectra Physics Ltd, St Albans, Herts AL1 5UF) which integrates negative (composite gas, $\mathrm{CO}_{2}$, from column 1) as well as positive $\left(\mathrm{H}_{2}\right.$, oxygen, $\mathrm{N}_{2}, \mathrm{CH}_{4}$ from final column) peaks of virtually unlimited size. This eliminates the need to change polarity and attenuation. The equipment was standardized using a mixture of $\mathrm{CO}_{2}-\mathrm{H}_{2}-\mathrm{N}_{2}-\mathrm{CH}_{4}$ $(25: 25: 25: 25$, by vol. $)$.

VFA were measured daily by a modification of the technique of Cottyn \& Boucque (1968). The apparatus was a Pye 104 gas-liquid chromatograph equipped with a flame-ionization detector, an S4 Autojector and a Spectra Physics SP4000 Chromatography Data System.

A glass column ( $1.52 \mathrm{~m} \times 6.4 \mathrm{~mm})$ packed with $100 \mathrm{~g}$ Carbowax 20M TPA/kg Chromsorb WHP 80-100 mesh (Field Instruments Co. Ltd, Twickenham, Middlesex TW1 4EG) was used. The column was operated at $150^{\circ}$ with argon $(50 \mathrm{ml} / \mathrm{min})$ as carrier gas. Samples $(0.6$ $\mathrm{ml}$ ) of fermenter liquid were pipetted into centrifuge-tubes (Eppendorf), mixed with $0.3 \mathrm{ml}$ diluent (100 mM-crotonic acid in $50 \mathrm{ml}$ orthophosphoric acid/1) and centrifuged ( $2 \mathrm{~min}$, $14000 \mathrm{rev} / \mathrm{min}$ ). The clear supernatant fraction was transferred to vials for direct injection of a standard $2 \mu \mathrm{l}$ sample onto the column. The crotonic acid which has a retention time greater than valeric acid but less than caproic acid was used as internal standard. The equipment was standardized using a mixture of acetic $(60 \mathrm{~mm})$, propionic $(20 \mathrm{~mm})$, butyric $(20 \mathrm{~mm})$, isovaleric $(10 \mathrm{~mm})$ and valeric acid $(10 \mathrm{mM})$ prepared in the same manner.

Microbial DNA was assayed daily by the diphenylamine reaction of Burton (1956). Duplicate $1 \mathrm{ml}$ samples of effluent liquid were taken daily and centrifuged (14000 rev/min,

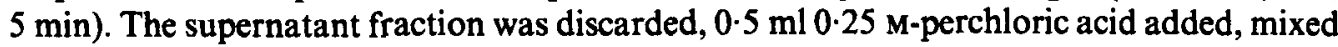
and centrifuged (14000 rev/min, $2 \mathrm{~min})$. The supernatant fraction was discarded and $1 \mathrm{ml}$ 0.25 M-perchloric acid mixed with the residue. The mixture was heated $\left(70^{\circ}, 30 \mathrm{~min}\right)$, centrifuged (14000 rev/min, $2 \mathrm{~min})$ and the whole supernatant fraction taken for the diphenylamine reaction. Calf thymus DNA $(0-200 \mu \mathrm{g} / \mathrm{ml})$ was used as standard.

\section{Calculations}

The net gas volume produced was calculated by subtracting the effluent liquid volume (l) from the total gas volume (1) collected in the butyl rubber bag. Gas volumes were measured at atmospheric pressure but were not corrected to STP. Using the percentage composition of the gas phase in the fermenter headspace, the volume of $\mathrm{CO}_{2}, \mathrm{H}_{2}$ and $\mathrm{CH}_{4}$ was calculated and converted to $\mathrm{mmol} / \mathrm{d}$. Results are means of single daily determinations.

Net VFA production ( $\mathrm{mmol} / \mathrm{d}$ ) was calculated by multiplying the concentration of the individual VFA ( $\mathrm{mmol} / \mathrm{l})$ in the effluent liquid by the volume of effluent collected per day. Results are means of single daily determinations over the $25 \mathrm{~d}$ treatment period.

Microbial matter produced ( $\mathrm{mmol} / \mathrm{d}$ ) was calculated using DNA measurements and the following assumptions: (a) DNA contains $140 \mathrm{mg} \mathrm{N} / \mathrm{g}$ (Ling \& Buttery, 1978); (b) there are $32 \mathrm{mg}$ DNA-N/g microbial-N (Allison, 1970); (c) there are $105 \mathrm{mg}$ microbial-N/g total microbial dry weight (Allison, 1970); (d) the molecular formula of microbes is $\mathrm{C}_{6} \mathrm{H}_{9 \cdot 85} \mathrm{O}_{2 \cdot 99} \mathrm{~N}_{1 \cdot 20}$ (Demeyer \& Van Nevel, 1975). Microbial yield was expressed in terms of $\mathrm{g}$ microbial-N/kg organic matter fermented $\left(\mathrm{OM}_{\mathrm{f}}\right)$.

The organic matter fermented was taken as the dry weight of substrate lost from the nylon bags each day. As most of the organic matter consists of anhydro-glucose units results are calculated on the basis that all loss of substrate was due to the fermentation of hexose. Hexose was taken as having a molecular weight of $162 \mathrm{~g}$ and division of the organic matter fermented each day $(\mathrm{g} / \mathrm{d})$ by 162 gave the amount of hexose fermented $(\mathrm{mmol} / \mathrm{d})$. 
Table 1. Expt 1. Effect of ICI 111075 and monensin on the production of hydrogen, methane and volatile fatty acids (VFA) and the substrate fermented in a continuous in vitro fermentation system

\begin{tabular}{|c|c|c|c|c|c|c|}
\hline & \multirow[b]{2}{*}{ Control } & \multicolumn{3}{|c|}{ ICI $111075(\mu \mathrm{g} / \mathrm{ml})$} & \multirow{2}{*}{$\begin{array}{c}\text { Monensin } \\
0.5 \mu \mathrm{g} / \mathrm{ml}\end{array}$} & \multirow[b]{2}{*}{ LSD $†$} \\
\hline & & 0.5 & $1 \cdot 0$ & $2 \cdot 0$ & & \\
\hline \multicolumn{7}{|l|}{ Gases $(\%$ composition) } \\
\hline $\mathbf{H}_{2}$ & $0 \cdot 14$ & 0.14 & 0.33 & $0 \cdot 51^{* *}$ & 0.03 & 0.22 \\
\hline $\mathrm{CH}_{4}$ & 8.04 & $4 \cdot 79^{* * *}$ & $2 \cdot 60^{* * *}$ & $0 \cdot 70^{* * *}$ & $1 \cdot 47^{* * *}$ & 1.58 \\
\hline \multicolumn{7}{|l|}{ VFA $(\mathrm{mmol} / \mathrm{d})$} \\
\hline Acetic & 30.93 & $31 \cdot 33$ & $33 \cdot 27$ & $31 \cdot 18$ & $27 \cdot 26$ & 3.75 \\
\hline Propionic & 7.80 & $10 \cdot 21^{*}$ & $12 \cdot 16^{* * *}$ & $13 \cdot 54^{* * *}$ & $9 \cdot 19^{*}$ & $1 \cdot 19$ \\
\hline Butyric & $3 \cdot 12$ & 3.04 & $3 \cdot 31$ & $3 \cdot 31$ & $1.82^{* * *}$ & 0.41 \\
\hline Hexose fermented $(\mathrm{mmol} / \mathrm{d})$ & $30 \cdot 77$ & $30 \cdot 52$ & $29 \cdot 82$ & 29.08 & $25 \cdot 00^{* * *}$ & 2.48 \\
\hline
\end{tabular}

$* P<0.05, * * P<0.01, * * * P<0.001$

$\dagger$ Least significant difference.

The recovery of hexose energy in fermentation end-products was calculated using the heats of combustion of the respective products. The heat of combustion of hexose was taken as $2832 \mathrm{~J} / \mathrm{mmol}$. The energy content of the microbial matter was calculated as $3262 \mathrm{~J} / \mathrm{mmol}$ assuming the average microbial composition was $(1 \mathrm{~kg})$ : 400 protein, 100 lipid, 100 carbohydrate, 200 nucleic acids, 200 cell wall.

The recovery of metabolic hydrogen $(2 \mathrm{H})$ was calculated using the method described by Marty \& Demeyer (1973). Lactate was not determined in samples of fermenter effluent liquid and was therefore not included in the equation to calculate $2 \mathrm{H}$ recovered in microbial cells.

Statistical analysis of the results was by an analysis of variance.

\section{RESULTS}

Expt 1. Dose response of methane inhibitor ICI 111075. The production of gases, VFA and the amount of hexose fermented are summarized in Table 1 as means for the $25 \mathrm{~d}$ treatment period. The production of $\mathrm{CH}_{4}$ was inhibited by 40,68 and $91 \%$ at doses of $0.5,1.0$ and $2.0 \mu \mathrm{g} \mathrm{ICI} 111075 / \mathrm{ml}$ respectively and was accompanied by a progressive increase in $\mathrm{H}_{2}$ production. Monensin treatment decreased both $\mathrm{CH}_{4}$ and $\mathrm{H}_{2}$ production.

ICI 111075 had no significant effect on acetate and butyrate production but increased propionate production above control values by 31,55 and $73 \%$ at doses of $0.5,1.0$ and $2.0 \mu \mathrm{g} / \mathrm{ml}$ respectively. Total VFA production was increased slightly. Monensin reduced acetate and butyrate production by 12 and $41 \%$ respectively while propionate production was increased by $18 \%$. Total VFA production, relative to the control, was reduced by $11 \%$.

ICI 111075 had no significant effect on the amount of hexose fermented although there was a slight downward trend at the higher doses. Monensin, however, had an immediate and maintained depressant effect on hexose digestion, the over-all reduction being $19 \%$.

Expt 2. Comparative effects of ICI 111075 and monensin. The net production of gases, VFA, microbial yield and the amount of hexose fermented are summarized in Table 2. ICI 111075 at $2.0 \mu \mathrm{g} / \mathrm{ml}$ reduced $\mathrm{CH}_{4}$ by $82 \%$, increased $\mathrm{H}_{2}$ 5-fold but did not affect $\mathrm{CO}_{2}$ production. Monensin at $0.5 \mu \mathrm{g} / \mathrm{ml}$ reduced $\mathrm{CH}_{4}$ by $57 \%, \mathrm{H}_{2}$ by $15 \%$ and $\mathrm{CO}_{2}$ production by $33 \%$.

ICI 111075 increased the net production of acetate, propionate and butyrate by 15,119 
Table 2. Expt 2. Effect of ICI 111075 and monensin on the net production of gases, volatile fatty acids (VFA) and microbial matter and the substrate fermented in a continuous in vitro fermentation system

\begin{tabular}{|c|c|c|c|c|}
\hline & Control & ICI 111075 & Monensin & $\mathrm{LSD}^{+}$ \\
\hline \multicolumn{5}{|l|}{ Gases (mmol/d) } \\
\hline $\mathrm{CO}_{2}$ & 27.35 & 27.51 & $18 \cdot 39^{* * * *}$ & $1 \cdot 77$ \\
\hline $\mathbf{H}$ & 0.13 & $0.65^{* * *}$ & 0.11 & 0.06 \\
\hline $\mathrm{CH}_{4}$ & 6.41 & $1 \cdot 22^{* * *}$ & $2 \cdot 75^{* * *}$ & 0.52 \\
\hline \multicolumn{5}{|l|}{ VFA $(\mathrm{mmol} / \mathrm{d})$} \\
\hline Acetic & $21 \cdot 04$ & $24 \cdot 23^{* * *}$ & $19 \cdot 47^{* *}$ & $1 \cdot 11$ \\
\hline Propionic & 6.51 & $14 \cdot 28^{* * *}$ & $8.09^{* * *}$ & 0.80 \\
\hline Butyric & 3.92 & $4 \cdot 16^{* *}$ & $2 \cdot 54^{* * *}$ & 0.18 \\
\hline Isovaleric & 0.69 & $0 \cdot 58^{* * *}$ & $0.62^{* * *}$ & 0.04 \\
\hline Valeric & 1.63 & 1.67 & $1-46^{* * *}$ & 0.07 \\
\hline Total & 33.75 & $44 \cdot 90^{* * *}$ & $32 \cdot 18$ & 1.92 \\
\hline Hexose fermented $(\mathrm{mmol} / \mathrm{d})$ & $31 \cdot 17$ & $31 \cdot 80$ & $25 \cdot 95^{* * *}$ & 0.71 \\
\hline VFA/hexose fermented & 1.08 & $1 \cdot 41^{* * *}$ & $1 \cdot 24^{* * *}$ & 0.06 \\
\hline Microbial yield (gN/kg OM $\ddagger$ ) & $14 \cdot 21$ & $12 \cdot 81$ & $13 \cdot 00$ & - \\
\hline
\end{tabular}

* $P<0.05,{ }^{* *} P<0.01,{ }^{* * *} P<0.001$.

$\dagger$ Least significant difference.

$\ddagger$ Organic matter fermented.

and $6 \%$ respectively. Since the total VFA production was increased by $33 \%$ the molar proportion of acetate fell from 0.62 to 0.54 whilst that of propionate rose from 0.19 to 0.32 . In comparison monensin reduced the net production of acetate and butyrate by 8 and $35 \%$ respectively while propionate production increased by $24 \%$. Total VFA production, however, was slightly depressed.

The amount of hexose fermented was increased slightly by ICI 111075 but was depressed by $17 \%$ with monensin. Both ICI 111075 and monensin improved the yield of VFA produced per unit hexose fermented by 31 and $15 \%$ respectively. (Table 2). The yield of microbial matter in terms of $\mathrm{g}$ microbial $\mathrm{N}$ per $\mathrm{kg}$ organic matter fermented was depressed by both treatments.

The recovery of hexose energy, $\mathrm{C}$ and $\mathrm{H}_{2}$ in fermentation products is summarized in Table 3. ICI 111075 and monensin increased the yield of hexose energy in VFA by 32 and $13 \%$ above control values respectively. This was accompanied by reductions in energy lost as $\mathrm{CH}_{4}$ of 82 and $49 \%$ and energy found in microbes by 10 and $8 \%$ for ICI 111075 and monensin respectively. The increased $\mathrm{H}_{2}$ production associated with ICI 111075 treatment only constituted a very small loss of substrate energy. Similar values were obtained for the recovery of hexose $\mathrm{C}$. The total recovery of metabolic $\mathrm{H}$ was only 69 and $73 \%$ with ICI 111075 and monensin respectively compared with a control recovery of $87 \%$.

Expt 3. Effect of dilution rate on the action of ICI 111075 and monensin. The production of gases, VFA, microbial yield and the amount of hexose fermented are summarized in Table 4 (high dilution rate) and Table 5 (low dilution rate) as means for the $25 \mathrm{~d}$ treatment period. In control fermentations reducing the dilution rate from 0.90 to $0.45 / \mathrm{d}$ increased $\mathrm{CO}_{2}$ and $\mathrm{CH}_{4}$ production by 64 and $40 \%$ respectively. The total net production of VFA was reduced by $15 \%$ despite a $9 \%$ increase in the hexose fermented. Consequently the yield of VFA per unit hexose fermented decreased from 1.33 to 1.06. The molar proportion of acetate rose from 0.60 to 0.67 while the proportion of propionate fell from 0.21 to 0.18 . The yield of microbial matter was reduced by $43 \%$ from $14 \cdot 16$ to $8.07 \mathrm{~g}$ microbial $\mathrm{N}$ per $\mathrm{kg}$ organic matter fermented. 
Table 3. Expt 2. Effect of ICI 111075 and monensin on the recovery of hexose energy, carbon and metabolic hydrogen in fermentation end-products

\begin{tabular}{|c|c|c|c|}
\hline & Control & ICI 111075 & Monensin \\
\hline \multicolumn{4}{|c|}{ Energy (\% hexose energy) } \\
\hline $\mathrm{H}$ & 0.01 & 0.05 & 0.01 \\
\hline $\mathrm{CH}_{4}$ & $6 \cdot 40$ & $1 \cdot 21$ & $3 \cdot 30$ \\
\hline VFA & $49 \cdot 40$ & $65 \cdot 12$ & $55 \cdot 72$ \\
\hline Microbial matter & $17 \cdot 20$ & $15 \cdot 56$ & $15 \cdot 77$ \\
\hline Total & 72.99 & 81.94 & 74.80 \\
\hline \multicolumn{4}{|l|}{$C(\%$ hexose $C)$} \\
\hline $\mathrm{CO}_{2}$ & $14 \cdot 62$ & $14 \cdot 41$ & $11 \cdot 83$ \\
\hline $\mathrm{CH}_{4}^{2}$ & $3 \cdot 43$ & 0.65 & $1 \cdot 77$ \\
\hline VFA & $47 \cdot 50$ & $62 \cdot 49$ & 53.80 \\
\hline Microbial matter & 14.97 & 13.49 & $13 \cdot 70$ \\
\hline Total & $80 \cdot 52$ & $91 \cdot 04$ & $81 \cdot 10$ \\
\hline \multicolumn{4}{|c|}{ Metabolic $\mathrm{H}$ (\% recovery)* } \\
\hline $\mathrm{H}$ & 0.17 & 0.74 & $0 \cdot 17$ \\
\hline $\mathrm{CH}_{4}$ & $35 \cdot 97$ & $5 \cdot 72$ & $17 \cdot 41$ \\
\hline VFA & $42 \cdot 32$ & $53 \cdot 28$ & $46 \cdot 60$ \\
\hline Microbial matter & $8 \cdot 68$ & $9 \cdot 54$ & $9 \cdot 29$ \\
\hline Total & $87 \cdot 14$ & $69 \cdot 28$ & $73 \cdot 47$ \\
\hline
\end{tabular}

* Metabolic H calculated using the equations described by Marty \& Demeyer (1973).

Table 4. Expt 3. Effect of ICI 111075 and monensin on the net production of gases, volatile fatty acids (VFA) and microbial matter and the substrate fermented in a continuous in vitro fermentation system running at a high dilution rate $(0.9 / d)$

\begin{tabular}{|c|c|c|c|c|}
\hline & Control & ICI 111075 & Monensin & LSD $\dagger$ \\
\hline \multicolumn{5}{|l|}{ Gases (mmol/d) } \\
\hline $\mathrm{CO}_{2}$ & 25.83 & $23 \cdot 72$ & $17 \cdot 71^{* * * *}$ & 2.94 \\
\hline $\mathrm{H}_{2}$ & 0.02 & $0 \cdot 23^{* * * *}$ & 0.03 & 0.06 \\
\hline $\mathrm{CH}_{4}$ & 8.71 & $1 \cdot 12^{* * *}$ & $4 \cdot 87^{* * *}$ & $1 \cdot 12$ \\
\hline \multicolumn{5}{|l|}{ VFA $(\mathrm{mmol} / \mathrm{d})$} \\
\hline Acetic & 27.58 & 25.46 & $23 \cdot 16^{* * *}$ & $2 \cdot 36$ \\
\hline Propionic & $9 \cdot 68$ & $12 \cdot 90^{* * *}$ & $10 \cdot 83$ & 1.22 \\
\hline Butyric & 4.91 & 4.78 & $3 \cdot 49^{* * *}$ & 0.38 \\
\hline Isovaleric & 0.89 & $1 \cdot 10^{*}$ & $1 \cdot 18^{* *}$ & 0.21 \\
\hline Valeric & 1.55 & 1.53 & $1.27^{* * *}$ & 0.13 \\
\hline Total & $45 \cdot 77$ & $46 \cdot 26$ & $40 \cdot 67^{* *}$ & 3.72 \\
\hline Hexose fermented $(\mathrm{mmol} / \mathrm{d})$ & $34 \cdot 15$ & $34 \cdot 20$ & $28 \cdot 76^{* * *}$ & $1 \cdot 16$ \\
\hline VFA/hexose fermented & 1.33 & 1.36 & 1.42 & 0.13 \\
\hline Microbial yield $\left(\mathrm{gN} / \mathrm{kg} \mathrm{OM}_{\mathrm{f}} \ddagger\right)$ & $14 \cdot 16$ & $12 \cdot 64$ & $12 \cdot 77$ & - \\
\hline
\end{tabular}

- $P<0.05,{ }^{* *} P<0.01, * * * P<0.001$.

$\dagger$ Least significant difference.

$\ddagger$ Organic matter fermented.

At the high dilution rate ICI 111075 reduced $\mathrm{CH}_{4}$ by $87 \%$ and $\mathrm{CO}_{2}$ by $8 \%$ but increased $\mathrm{H}_{2}$ 12-fold. At the low dilution rate a similar pattern of effects was observed but with a much greater reduction in $\mathrm{CO}_{2}$ and greater increase in $\mathrm{H}_{2}$ which accompanied the inhibition of $\mathrm{CH}_{4}$. At both dilution rates acetate was reduced by $7 \%$ while propionate was increased by 33 and $60 \%$ at high and low dilution rates respectively. Total VFA production was increased slightly and the hexose fermented was reduced slightly at both dilution rates but neither 
Table 5. Expt 3. Effect of ICI 111075 and monensin on the net production of gases, volatile fatty acids (VFA) and microbial matter and the substrate fermented in a continuous in vitro fermenter running at a low dilution rate $(0.45 / d)$

\begin{tabular}{|c|c|c|c|c|}
\hline & Control & ICI 111075 & Monensin & LSD + \\
\hline \multicolumn{5}{|l|}{ Gases (mmol/d) } \\
\hline $\mathrm{CO}_{2}$ & $42 \cdot 33$ & $33.81 * * *$ & $26 \cdot 53^{* * *}$ & $2 \cdot 73$ \\
\hline $\mathrm{H}_{2}$ & 0.01 & $1 \cdot 21^{* * *}$ & 0.02 & 0.20 \\
\hline $\mathrm{CH}_{4}$ & $12 \cdot 19$ & $2 \cdot 01 * * *$ & $6 \cdot 55^{* * *}$ & 0.98 \\
\hline \multicolumn{5}{|l|}{$\mathrm{VFA}(\mathrm{mmol} / \mathrm{d})$} \\
\hline Acetic & $25 \cdot 06$ & $23 \cdot 56$ & $19 \cdot 98^{* * *}$ & 1.79 \\
\hline Propionic & $7 \cdot 18$ & $11 \cdot 49^{* * *}$ & $10 \cdot 85^{* * *}$ & 0.95 \\
\hline Butyric & $4 \cdot 56$ & 4.33 & $3 \cdot 32 * * *$ & 3.46 \\
\hline Isovaleric & 0.49 & 0.49 & 0.50 & 0.06 \\
\hline Valeric & $1 \cdot 20$ & $1.63 * * *$ & $0.85^{* * *}$ & 0.14 \\
\hline Total & 39.04 & $41 \cdot 80^{*}$ & $35 \cdot 59^{*}$ & $2 \cdot 71$ \\
\hline Hexose fermented $(\mathrm{mmol} / \mathrm{d})$ & $37 \cdot 18$ & $36 \cdot 14$ & $30 \cdot 30 * * *$ & 1.52 \\
\hline VFA/hexose fermented & 1.06 & $1 \cdot 16^{*}$ & $1 \cdot 20^{* *}$ & 0.09 \\
\hline Microbial yield (gN/kg OMt & $8 \cdot 07$ & $9 \cdot 20$ & $9 \cdot 19$ & - \\
\hline
\end{tabular}

$* P<0.05, * * P<0.01, * * * P<0.001$.

$\dagger$ Least significant difference.

$\ddagger$ Organic matter fermented.

was statistically significant. The yield of VFA per unit hexose fermented (Tables 4 and 5) was not affected at the high dilution rate but showed a $9 \%$ improvement at the low dilution rate. The yield of microbial matter was reduced by $11 \%$ and increased by $14 \%$ at high and low dilution rates respectively.

Monensin reduced $\mathrm{CH}_{4}$ production by 44 and $46 \%$ and $\mathrm{CO}_{2}$ by 31 and $37 \%$ at high and low dilutions respectively. $\mathrm{H}_{2}$ production was not increased. Acetate production was reduced by 16 and $20 \%$, butyrate production reduced by 29 and $27 \%$ and propionate production increased by 12 and $51 \%$ at high and low dilution rates respectively. Total VFA production was reduced by 11 and $9 \%$ and the hexose fermented reduced by 16 and $19 \%$ at high and low rates respectively. Consequently the yield of VFA per unit hexose fermented (Tables 4 and 5) was improved by $7 \%$ at high dilution and by $13 \%$ at low dilution. The yield of microbial matter was reduced by $10 \%$ and increased by $14 \%$ at high and low dilutions respectively.

The recovery of hexose energy, $\mathrm{C}$ and $\mathrm{H}_{2}$ in fermentation products is summarized in Table 6. In the low dilution rate control fermentation the recovery of hexose energy was $23 \%$ lower in VFA and $43 \%$ lower in microbial matter in comparison with a high dilution rate control. Losses of hexose energy as $\mathrm{CH}_{4}$ increased by $28 \%$ and losses of hexose $\mathrm{C}$ as $\mathrm{CO}_{2}$ were increased by $51 \%$. The total recoveries of hexose energy were 84 and $65 \%$ in the high and low dilution rate controls respectively.

ICI 111075 increased the recovery of hexose energy in VFA by 6 and $16 \%$ at high and low dilution rates. Recoveries of energy in microbial matter were reduced by $10 \%$ at high dilution rate but increased by $15 \%$ at low dilution rate. Losses of hexose energy as $\mathrm{CH}_{4}$ were reduced by 87 and $83 \%$ respectively. Similar patterns were recorded for $\mathrm{C}$ recoveries. Treatment with ICI 111075 reduced the total recovery of metabolic $\mathrm{H}$ by 22 and $35 \%$ relative to controls at high and low dilution rates respectively.

Monensin increased the yield of hexose energy in VFA by $8 \%$ at high dilution and by $16 \%$ at low dilution. Energy in microbial matter was reduced by $10 \%$ at high dilution but 
Table 6. Expt 3. Effect of ICI 111075, monensin and dilution rate on the recovery of hexose energy, carbon and metabolic hydrogen in fermentation end-products

\begin{tabular}{|c|c|c|c|c|c|c|}
\hline & \multicolumn{3}{|c|}{ High dilution } & \multicolumn{3}{|c|}{ Low dilution } \\
\hline & Control & ICI 111075 & Monensin & Control & ICI 111075 & Monensin \\
\hline \multirow{2}{*}{\multicolumn{7}{|c|}{ Energy ( $\%$ hexose energy) }} \\
\hline $\mathrm{H}$, & & & *- & * - & 0.08 & $*$ \\
\hline $\mathrm{CH}_{4}$ & 7.96 & 1.04 & 5.29 & $\overline{10 \cdot 21}$ & 1.72 & 6.73 \\
\hline VFA & 58.61 & 61.94 & 63.23 & $45 \cdot 37$ & 52.55 & 52.75 \\
\hline Microbial matter & $17 \cdot 17$ & 15.38 & 15.46 & 9.77 & 11.20 & $11 \cdot 12$ \\
\hline Total & 83.74 & 78.37 & 83.29 & $65 \cdot 35$ & 65.55 & $70 \cdot 60$ \\
\hline \multicolumn{7}{|l|}{$\mathrm{C}(\%$ hexose $\mathrm{C})$} \\
\hline $\mathrm{CO}_{2}$ & $12 \cdot 61$ & $11 \cdot 58$ & $10 \cdot 28$ & $18 \cdot 98$ & $15 \cdot 60$ & 14.57 \\
\hline $\mathrm{CH}_{4}$ & $4 \cdot 27$ & 0.53 & 2.80 & 5.45 & 0.92 & 3.62 \\
\hline VFA & 56.61 & 59.46 & 60.79 & 44.04 & 50.54 & 50.92 \\
\hline Microbial matter & 14.88 & $13 \cdot 32$ & 13.42 & 8.52 & $9 \cdot 72$ & 9.62 \\
\hline Total & 88.37 & 84.89 & 87.29 & 76.99 & 76.78 & 78.73 \\
\hline \multicolumn{7}{|c|}{ Metabolic H (\% recovery)t } \\
\hline $\mathrm{H}_{2}$ & 0.02 & 0.25 & 0.04 & 0.01 & 1.47 & 0.03 \\
\hline $\mathrm{CH}_{4}$ & 37.95 & $4 \cdot 76$ & $24 \cdot 82$ & $60 \cdot 50$ & 9.77 & 38.45 \\
\hline VFA & $42 \cdot 45$ & 50.56 & 49.00 & $37 \cdot 50$ & 48.79 & $49 \cdot 51$ \\
\hline Microbial matter & 8.89 & $9 \cdot 22$ & 9.31 & 8.74 & 9.23 & 9.53 \\
\hline Total & 89.31 & 64.79 & 83.17 & 106.75 & 69.26 & 97.52 \\
\hline
\end{tabular}

- $P<0.005$.

+ Metabolic H calculated using the equations described by Marty \& Demeyer (1973).

increased by $14 \%$ at low dilution. Losses of energy as $\mathrm{CH}_{4}$ were higher than those with ICI 111075 being only $34 \%$ lower than control at both dilution rates. Losses of hexose C as $\mathrm{CO}_{8}$ were reduced by 18 and $23 \%$ at high and low dilution rates respectively. Again similar effects were seen with $\mathrm{C}$ recoveries. The total recoveries of hexose energy and $\mathrm{C}$ were not affected greatly by monensin treatment. Total recoveries of metabolic $\mathrm{H}$ were only reduced by 7 and $9 \%$ relative to controls at high and low dilution rates respectively.

\section{DISCUSSION}

The ability to control strictly fermentation conditions is an important advantage when using a simple continuous fermenter to study the effects of rumen manipulators in vitro. A stable fermentation can normally be achieved in 5-7 d and the agreement between different fermenters is demonstrated by the following means ( $\pm \mathrm{SE} ; \mathrm{mmol} / \mathrm{d}$ ) calculated from single daily determinations for six fermenters over $5 \mathrm{~d}$ (Expt 2); total VFA 39.77 \pm 0.02 , $\mathrm{CH}_{4} 10.67 \pm 0.04$ and hexose fermented 33.55 \pm 0.04 .

Similar fermenters have been shown to behave in a manner comparable to the in vivo situation (Czerkawski \& Breckenridge, 1977) and should provide a useful tool with which to study the quantitative effects of chemical manipulators.

Expt 1 showed that the effects of a $\mathrm{CH}_{4}$ inhibitor, ICI 111075 could be maintained over a $25 \mathrm{~d}$ period in a dose-related manner. Inhibition of $\mathrm{CH}_{4}$ was accompanied by increased levels of $\mathrm{H}$ and propionic acid and is, therefore, similar to the effects of other $\mathrm{CH}_{4}$ inhibitors (Van Nevel et al. 1969; Trei, Parish, Singh et al. 1971; Marty \& Demeyer, 1973). Monensin reduced substrate digestion and production of $\mathrm{CH}_{4}$, acetate, butyrate and total VFA but increased propionate production. The profile of activity was comparable with other in vitro experiments (Richardson et al. 1976; Van Nevel \& Demeyer, 1977; Slyter, 1979).

Expt 2 demonstrated that both manipulators increased the yield of hexose energy, $\mathrm{C}$ and 
2H in VFA. ICI 111075 increased total VFA production, mainly as a result of increased propionate. A small increase in hexose fermented was also observed. Monensin, however, reduced total VFA production although the molar proportion of propionate increased. Since the amount of hexose fermented was substantially reduced the yield of VFA per unit hexose fermented was increased. These improvements were balanced by reductions in $\mathrm{CH}_{4}$ production of 81 and $57 \%$ and reductions in microbial yield of 10 and $9 \%$ for ICI 111075 and monensin respectively.

Monensin has reduced microbial cell yields in batch culture (Van Nevel \& Demeyer, 1977) and in semi-continuous batch culture (Short, 1978) using micro-organisms unadapted to the compound. Short (1978) using rumen fluid from sheep previously receiving monensin found that cell yield was not reduced by further addition of monensin. No indications of adaptation have been observed in the continuous fermenters over a $25 \mathrm{~d}$ period using the factors of microbial yield or substrate digestion.

ICI 111075 produced little effect on digestibility while monensin had a consistent inhibitory effect. Short (1978) found that monensin had no effect on cellulose digestion in rumen fluid from animals 'adapted' to monensin. Lemenager et al. (1978) found that monensin depressed digestibility in fluid from both control and monensin-treated steers but the effect was less in the latter instance where it was noted that the basal level of digestion was already lower than in the control group. This is in agreement with results (Davies \& Stanier, unpublished results) obtained using fluid previously treated with monensin for a $25 \mathrm{~d}$ period in a continuous fermenter.

Other differences between ICI 111075 and monensin were: (a) the consistent reduction of $\mathrm{CO}_{2}$ production with monensin which was not entirely due to the depression of hexose fermentation while the $\mathrm{CH}_{4}$ inhibitor had little effect; (b) the large increase in $\mathrm{H}_{2}$ production accompanying the depression of $\mathrm{CH}_{4}$ production with ICI 111075 while monensin tended to reduce $\mathrm{H}_{2}$ below control values, the latter being in agreement with Slyter (1979).

The results highlight the different effects these manipulators have on the rumen fermentation and show that both increase the yield of hexose energy in VFA which are likely to benefit animal performance.

Monensin treatment reduces rumen dilution rate by $31 \%$ in steers (Lemenager et al. 1978) and by $42 \%$ in sheep (Allen \& Harrison, 1979). The effects of changing dilution rate have been demonstrated in vivo (Harrison et al. 1974; Harrison et al. 1975; Thomson et al. 1975; Thomson et al. 1978). Expt 3 was designed to show the effects of dilution rate on the action of ICI 111075 and monensin. In control fermenters reducing the dilution rate from $0.90 / \mathrm{d}$ to $0.45 / \mathrm{d}$ increased the hexose fermented but reduced the net production of VFA. Consequently the yield of VFA per unit hexose fermented was reduced by $20 \%$. Losses of hexose as $\mathrm{CO}_{2}$ and $\mathrm{CH}_{4}$ were increased greatly at the low dilution rate. The conversion of VFA to $\mathrm{CO}_{2}$ and $\mathrm{CH}_{4}$ has been reported by Isaacson et al. (1975); Rowe et al. (1979) and A. Davies, M. L. Loughnan, J. V. Nolan and R. A. Leng, unpublished results. Rowe et al. (1979) isolated considerable numbers of Methanosarcina from sheep fed molasses-based diets. They concluded that their presence indicated that secondary fermentation was occurring in the rumen and that this could explain the conversion of acetate- $\mathrm{C}$ to $\mathrm{CO}_{2}$. It was also noted that rumen dilution rates are very low on the diets used. These results are, therefore, comparable with those obtained in the fermenters and the secondary fermentation of VFA to $\mathrm{CO}_{2}$ and $\mathrm{CH}_{4}$ may well be the reason for the observed low yield of VFA which accompanied a large increase in $\mathrm{CO}_{2}$ and $\mathrm{CH}_{4}$ production at the low dilution rate. The molar proportions of VFA were not affected significantly by the dilution rates used but the yield of microbial matter was reduced by $43 \%$ at the low dilution rate. The latter was in agreement with Owens \& Isaacson (1977).

The addition of ICI 111075 and monensin produced the expected effects on the 
fermentation. The responses were similar at both dilution rates apart from a much greater increase in propionate production at the low dilution rate. Consequently the recovery of hexose energy and $\mathrm{C}$ in VFA showed a much greater improvement under these conditions. Both compounds increased the yield of microbial matter by $14 \%$ at the low dilution rate but reduced it by $10 \%$ at the high dilution rate.

Calculation of metabolic $\mathrm{H}$ recoveries using the established stoichiometry described by Marty \& Demeyer (1973) and Demeyer \& Van Nevel (1975) resulted in control recoveries of 89 and $106 \%$ at high and low dilution rates respectively. Monensin gave recoveries of 83 and $98 \%$ while ICI 111075 gave recoveries of only 65 and $69 \%$ at high and low dilution rates respectively. Clearly in the case of the $\mathrm{CH}_{4}$ inhibitor the stoichiometric equations do not account for a large proportion of the metabolic $\mathrm{H}$ produced. The latter is in agreement with Marty \& Demeyer (1973) who found that recoveries of metabolic $\mathrm{H}$ were low with a variety of $\mathrm{CH}_{4}$ inhibitors. The recovery of metabolic $\mathrm{H}$ in VFA was increased by 19 and $15 \%$ relative to control with ICI 111075 and monensin respectively. At the low dilution rate this effect was greater, recoveries in VFA being increased by 30 and 32\% with ICI 111075 and monensin respectively.

The theoretical hexose fermented calculated from the equations described by Marty \& Demeyer (1973) gave values 24,22 and $25 \%$ less than the observed values for control, ICI 111075 and monensin fermentations respectively, at a high dilution rate.

At the low dilution rate the theoretical hexose fermented was 40,34 and $34 \%$ less than the observed values for control, ICI 111075 and monensin fermentations respectively. The theoretical calculations predicted a reduced fermentation of hexose at the low dilution rate relative to the high dilution rate when in fact a slight increase was observed. These results may indicate an overestimation of the observed hexose fermented or the formation of end-products not included in the equation to calculate the hexose fermented. Use of the calculated hexose fermented increases substantially the values for microbial yield giving a range of $13-22 \mathrm{~g} \mathrm{~N} / \mathrm{kg} \mathrm{OM}$ over all treatments in Expts 2 and 3. This compares with a range of 8-14 $\mathrm{g} \mathrm{N} / \mathrm{kg} \mathrm{OM}$ using the observed values.

The experiment of Allen \& Harrison (1979) showed that treating sheep with monensin increased total VFA production and organic matter digestion, but resulted in no change in VFA yield. The efficiency of microbial growth was markedly reduced. These results were compatible with the observed reduction in rumen dilution rate which accompanied treatment with monensin. In the present study an analogous system was proposed which could possibly predict the in vivo effects of monensin by comparing results of a high-dilution rate control fermenter with that of a low-dilution-rate-monensin-treated fermenter. The results show that quantitatively a combination of monensin treatment and a reduction in dilution rate cancel out the improved VFA yield observed with monensin treatment alone. The reduction in fermented hexose due to monensin was less in the combined treatment as a result of the increase in hexose fermentation at the lower dilution rate. Relative to a high-dilution-rate control microbial yield was depressed when monensin treatment was accompanied by a low dilution rate. The in vitro results are therefore comparable with the results of Allen \& Harrison (1979) and suggest that where chemical manipulators of rumen fermentation also reduce dilution rate the net effect on the system may depend on the balance between often opposing shifts in the fermentation.

In summary the results show that the effects of two different types of rumen manipulator can be maintained, quantified and compared using a continuous fermentation system. The responses obtained were similar to those found in vivo. Using in vivo results the effect of dilution rate was demonstrated and it was shown that the net effect of chemical manipulators on the rumen fermentation can be modified substantially by additional effects such as a reduction in dilution rate. The practical implications of the results are likely to involve 
changes in food intake, increased importance of secondary fermentations and reduced effects of nutrients not degraded in the rumen.

The authors gratefully acknowledge the technical assistance provided by Miss S. Lewis and Mr S. Duckworth and thank the Research Engineering Laboratory, ICI Ltd, for the construction of the fermentation apparatus.

\section{REFERENCES}

Allen, J. D. \& Harrison, D. G. (1979). Proc. Nutr. Soc. 38, 32A.

Allison, M. J. (1970). In Physiology of Digestion and Metabolism in the Ruminant [A. T. Phillipson, editor]. Newcastle-upon-Tyne: Oriel Press, Ltd.

Bales, G. L., Kellog, D. W. \& Miller, D. D. (1976). J. Dairy Sci. 59, 1850.

Burton, K. (1956). Biochem. J. 62, 315.

Chalupa, W. (1977). J. Anim. Sci. 46, 585.

Chalupa, W. (1979). Vth int. Symp. on Ruminant Physiology, Clermont-Ferrand.

Clapperton, J. L. (1977). Anim. Prod. 24, 169.

Cole, N. A. \& McCroskey, J. E. (1975). J. Anim. Sci. 41, 1735.

Cottyn, B. G. \& Boucque, C. V. (1968). J. agric. Fd Chem. 16, 105.

Czerkawski, J. W. \& Breckenridge, G. (1977). Br. J. Nutr. 38, 371.

Czerkawski, J. W. \& Clapperton, J. L. (1968a). Lab. Pract. 17, 994.

Czerkawski, J. W. \& Clapperton, J. L. (1968b). Lab. Pract. 17, 1012.

Davis, G. V. \& Erhart, A. B. (1976). J. Anim. Sci. 43, 1.

Demeyer, D. I. \& Van Nevel, C. J. (1975). In Digestion and Metabolism in the Ruminant, p. 366 [I. W. McDonald and A. C. I. Warner, editors]. Armidale, New South Wales: University of New England Publishing Unit.

Gill, D. R., Martin, J. R. \& Lake, R. (1976). J. Anim. Sci. 43, 363.

Harrison, D. G., Beever, D. E. \& Thomson, D. J. (1974). Proc. Nutr. Soc. 33, 43 A.

Harrison, D. G., Beever, D. E., Thomson, D. J. \& Osbourn, D. F. (1975). J. agric. Sci., Camb. 85, 93.

Isaacson, H. R., Hinds, F. C., Bryant, M. P. \& Owens, F. N. (1975). J. Dairy Sci. 58, 1645.

Johnson, D. E. (1974). J. Anim. Sci. 38, 154.

Johnson, R. J., Herlugson, M. L., Ojikutu, L. B., Cordova, G., Dyer, I. A., Zimmer, P. \& De Lay, R. (1979). J. Anim. Sci. 48, 1338.

Joyner, A. E., Jr., Brown, L. J., Fogg, T. J. \& Rossi, T. (1979). J. Anim. Sci. 48, 1065.

Leibholz, J. (1975). Anim. Prod. 20, 93.

Lemenager, R. P., Owens, F. N., Shockey, B. J., Lusby, K. S. \& Totusek, R. (1978). J. Anim. Sci. 47, 255.

Ling, J. R. \& Buttery, P. J. (1978). Br. J. Nutr. 39, 165.

Marty, R. J. \& Demeyer, D. I. (1973). Br. J. Nutr. 30, 369.

Nockels, C. F., Jackson, D. W. \& Berry, B. W. (1978). J. Anim. Sci. 47, 788.

Oliver, W. M. (1975). J. Anim. Sci. 41, 999.

Owens, F. N. \& Isaacson, H. R. (1977). Fedn Proc. Fedn Am. Socs exp. Biol. 36, 198.

Perry, T. W., Beeson, W. M. \& Mohler, M. T. (1976). J. Anim. Sci. 42, 761.

Potter, E. L., Cooley, C. O., Richardson, L. F. \& Raun, A. P. (1976). J. Anim. Sci. 43, 665.

Raun, A. P., Cooley, C. O., Potter, E. L., Rathmacher, R. P. \& Richardson, L. F. (1976). J. Anim. Sci. 43, 670.

Richardson, L. F., Raun, A. P., Potter, E. L., Cooley, C. O. \& Rathmacher, R. P. (1976). J. Anim. Sci. 43, 657.

Rowe, J. B., Loughnan, M. L., Nolan, J. V. \& Leng, R. A. (1979). Br. J. Nutr. 41, 393.

Sawyer, M. S., Hoover, W. H. \& Sniffen, C. J. (1974). J. Anim. Sci. 38, 908.

Short, D. E. (1978). Rumen fermentation and nitrogen metabolism as affected by monensin. PhD thesis. University of Illinois, Urbana-Champaign.

Slyter, L. L. (1979). Appl. env. Microbiol. 37, 283.

Tamminga, S. (1976). Manipulating methane production in Ruminants. MSc thesis, University of Newcastle-upon-Tyne.

Thomson, D. J., Beever, D. E., Latham, M. J., Sharpe, M. E. \& Terry, R. A. (1978). J. agric. Sci., Camb. 91, 1.

Thomson, D. J., Beever, D. E., Mundell, D. C., Elderfield, M. L. \& Harrison, D. J. (1975). Proc. Nutr. Soc. 34, $111 \mathrm{~A}$.

Trei, J. E., Parish, R. C. \& Scott, G. C. (1971). J. Anim. Sci. 33, 1171.

Trei, J. E., Parish, R. C., Singh, Y. K. \& Scott, G. C. (1971). J. Dairy Sci. 54, 536.

Trei, J. E. \& Scott, G. C. (1971a). J. Anim. Sci. 33, 301.

Trei, J. E. \& Scott, G. C. (1971 b). J. Anim. Sci. 33, 311.

Trei, J. E., Scott, G. C. \& Parish, R. C. (1972). J. Anim. Sci. 34, 510.

Turner, H. A., Raleigh, R. J. \& Young, D. C. (1977). J. Anim. Sci. 44, 338.

Van Nevel, C. J. \& Demeyer, D. I. (1977). Appl. env. Microbiol. 34, 251.

Van Nevel, C. J. \& Demeyer, D. I. (1979). Ann. Rech. Vet. 10, 338.

Van Nevel, C. J., Hendrickx, H. K., Demeyer, D. I. \& Martin, J. (1969). Appl. Microbiol. $17,695$. 